\title{
Appendiceal orifice: more than it meets the eye
}

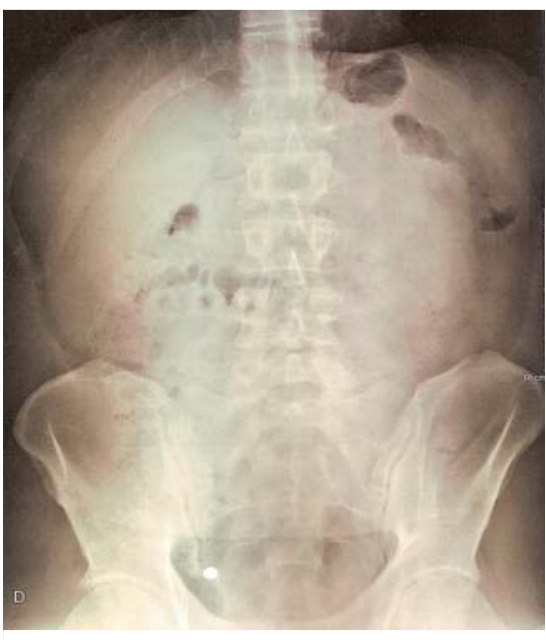

- Fig. 1 Abdominal X-ray showing a radiopaque image in the right inferior quadrant.

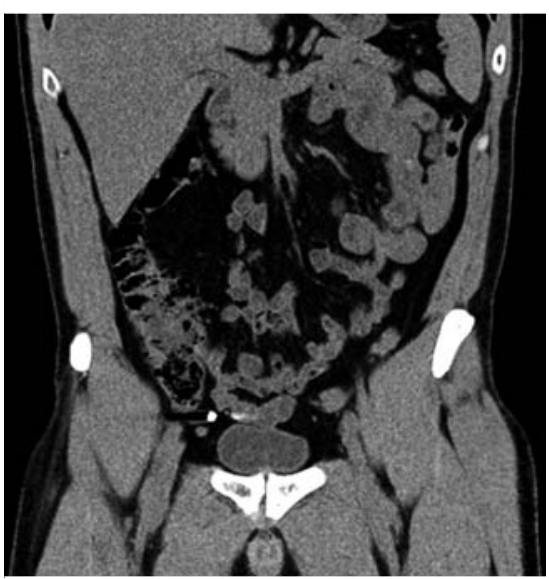

- Fig. 2 Abdominopelvic computed tomography scan showing a metallic-density image apparently within the cecal appendix without evidence of an inflammatory process.

A healthy and asymptomatic 38-year-old man presented with accidental foreign body ingestion. The abdominal X-ray showed a radiopaque image in the right inferior quadrant ( $>$ Fig. 1). An abdominopelvic computed tomography (CT) scan was performed and showed a metallic-density image apparently within the

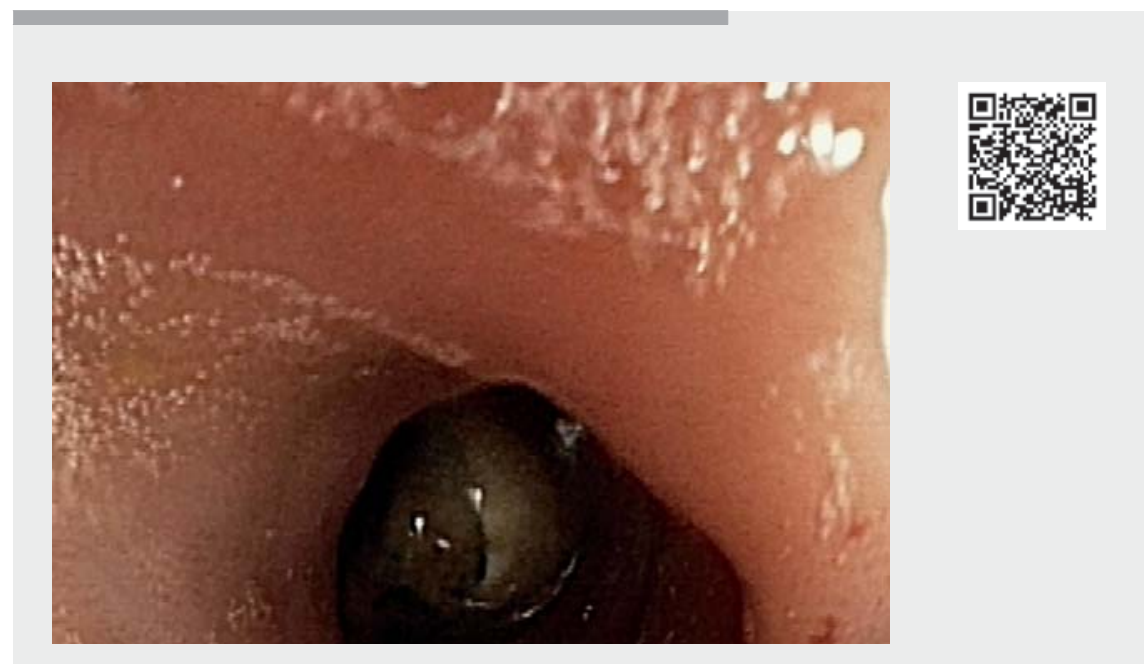

Video 1 Retrieval of a foreign body from the inside of the appendix.

cecal appendix without evidence of an inflammatory process ( $\triangleright$ Fig. 2).

In this context, the patient was submitted to a colonoscopy and there was no evidence of a foreign body after intubation of the cecum and observation of the appendiceal orifice. After several attempts to access the appendiceal orifice using a grasping forceps, an object was identified as a dental implant ( $\triangleright$ Video 1 ). It was removed and then retrieved using a snare ( $\triangleright$ Fig.3). The patient remained well and asymptomatic after the procedure.

Foreign bodies in the appendix have been described and complications such as acute appendicitis and appendiceal abscess can occur, especially with sharp, stiff, and metallic objects [1]. Endoscopic removal of the object has been suggested when an object is identified in the appendiceal orifice and there is no evidence of inflammation or other complication [2]. Clinical and imagiological follow-up is also an option, and some patients will have spontaneous expulsion of the object [3]. Nonetheless, surgery is indicated when endoscopic or spontaneous removal is not possible or when

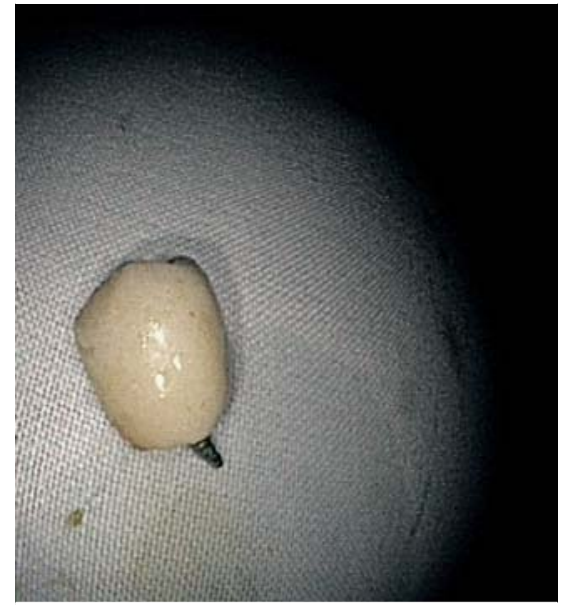

Fig. 3 Dental implant retrieved from the appendix.

there are signs of peritoneal inflammation $[1,4,5]$.

To the best of our knowledge, this is the first reported case of endoscopic removal of a foreign body inside of the appendix. In conclusion, patients presenting with foreign body ingestion and radiological image in the right lower abdominal quadrant may present with a broad spec- 
trum of severity. The endoscopist must keep in mind the possibility of a foreign body lodged in the appendix and the possibility of its endoscopic removal. However, it is mandatory to exclude the presence of an inflammatory process, which may warrant emergency surgery.

Endoscopy_UCTN_Code_CCL_1AD_2AH

\section{Competing interests}

The authors declare that they have no conflict of interest.

\section{The authors}

\section{Cláudia Pinto ${ }^{1}$, Rui Silva ${ }^{1,2}$}

1 Gastroenterology Department, Francisco Gentil Portuguese Institute for Oncology of Porto, Porto, Portugal

2 Gastroenterology Department, Santa Casa da Misericórdia, Vila do Conde, Portugal
Corresponding author

\section{Cláudia Pinto, MD}

Gastroenterology Department, Portuguese Oncology Institute of Porto, Rua Dr. António Bernardino de Almeida 865, 4200-072, Porto, Portugal

claudia.marquespinto@gmail.com

\section{References}

[1] Klingler P, Seelig M, DeVault K et al. Ingested foreign bodies within the appendix: a 100year review of the literature. Dig Dis 1998; 16: 308-314

[2] Ikeda K, Nakamura T, Uose S et al. Colonoscopic removal of a denture migrated in the appendix. Gastrointest Endosc 2018; 87: 893-894

[3] Volovelsky O, Gross E, Shteyer E. Appendicular foreign body: patience needed. J Pediatr Surg 2013; 48: 454-455

[4] Zhou J, Yu Y, Li K. Man with accidentally swallowed dental C+ file. Ann Emerg Med 2019; 73: 117-169

[5] Benizri El. Swallowing a safety pin: report of a case. World J Gastrointest Surg 2012; 4: 20
Bibliography

Endoscopy 2022; 54: E336-E337

DOI 10.1055/a-1532-1609

ISSN $0013-726 \mathrm{X}$

published online 19.7.2021

(C) 2021. Thieme. All rights reserved.

Georg Thieme Verlag KG, Rüdigerstraße 14 , 70469 Stuttgart, Germany

\section{ENDOSCOPY E-VIDEOS}

https://eref.thieme.de/e-videos

Endoscopy E-Videos is an open access online section, 靣话: reporting on interesting cases and new techniques in gastroenterological endoscopy. All papers include a high quality video and all contributions are freely accessible online. Processing charges apply (currently EUR 375), discounts and wavers acc. to HINARI are available.

This section has its own submission website at

https://mc.manuscriptcentral.com/e-videos 